\title{
El educador en contextos de encierro, un campo en tensión permanente
}

\author{
Prof. Yanina Verstraete \\ Docente de nivel medio en contextos de encierro \\ @ [ lyaniverstraete@hotmail.com ]
}

DOI: http://dx.doi.org/10.19137/huellas-2018-2216

\begin{abstract}
T as presentes reflexiones se contextualizan en el ejercicio de la prácti_ca docente ${ }^{1}$ que venimos desarrollando desde hace aproximadamente cuatro años en el sistema penitenciario. En ese marco surge el interrogante en torno a qué decisiones y acciones institucionales son necesarias para "neutralizar" las situaciones propias de la lógica carcelaria, que afectan el derecho a la educación. La problemática planteada parte de una perspectiva crítica centrada en la idea de conflicto en lo que respecta a la educación dentro de la institución carcelaria. En este marco, la escuela es un aparato de hegemonía que construye consenso en la población ajustando el discurso a los requerimientos del sistema económico y político. Entender a la escuela desde esta perspectiva, implica pensarla como un ámbito atravesado por relaciones de poder en donde se legitiman determinados modos de pensar. Pero que también, posibilita generar otras representaciones que cuestionen lo establecido y abran las puertas para construir alternativas que contribuyan a producir espacios de intervención creadora.

Consideramos que una de las formas de "neutralizar" la lógica carcelaria en la educación en contexto de encierro es analizando nuestra práctica educativa. Es fundamental autoevaluarnos y preguntarnos cómo vemos nuestro espacio de intervención en las aulas, la perspectiva de la que partimos, ya que ésta es medular, para luego actuar y aplicar la práctica desde un enfoque realmente basado en derechos humanos. Como nos enseña Freire (1999, p. 43): "La práctica educativa, la formación humana implica
\end{abstract}

1 El presente trabajo se encuadra en el informe final de un coloquio realizado en la Especialización Superior Docente en Educación en Contextos de Encierro, realizado en convenio entre La Dirección General de Educación Superior y la Dirección de Educación Permanente de Jóvenes y Adultos de la Provincia de La Pampa. 
opciones, rupturas, decisiones, estar y ponerse en contra, a favor de un sueño y contra otro, a favor de alguien y contra alguien". De esta manera, es conveniente preguntarnos qué práctica educativa, qué fines y objetivos perseguimos en nuestra tarea cotidiana.

Como educadores en contextos de privación de libertad ambulatoria debemos ejercer una práctica educativa desde la perspectiva de los derechos humanos dando lugar de esta manera, a la habilitación de la palabra, de la voz. Sin negar ni borrar el pasado del sujeto, sino partiendo de la idea de que este puede ser transformador de su realidad y metas pudiendo salir de aquel estado/ situación de vulnerabilidad social en el que se encuentra.

Identificar las decisiones y acciones institucionales que son necesarias para neutralizar las situaciones propias de la lógica carcelaria, que afectan el derecho a la educación, va unida al rol que puede llegar a tener el docente en ella. Dicho de otro modo, es interesante analizar las distintas categorías en las que pueden posicionarse los educadores para llevar a cabo posibles decisiones y acciones que neutralicen la lógica carcelaria que afecta el derecho a la educación.

Giroux y Aronowitz (1998) proponen algunas categorías posibles en las que puede posicionarse un docente en su práctica cotidiana. Estas son las siguientes: "Intelectuales transformadores, intelectuales críticos, intelectuales acomodaticios e intelectuales hegemónicos". Si bien el objetivo no es describirlas, sí vamos a tratar de interpretar cuál de todas estas categorías debería ser la que consideramos que debe posicionarse todo aquel que intente romper con toda lógica carcelaria que afecte a la educación como derecho en sí.

A pesar de que un educador puede pasar de una categoría a otra según las circunstancias, consideramos que para dar respuesta a la problemática planteada lo más adecuado es trabajar con docentes que se posicionen como transformadores porque esto los coloca como profesionales comprometidos, que asimilan la existencia de determinadas situaciones y relaciones de poder. En ese marco nos proponemos tratar de desarrollar en los estudiantes una comprensión en la que estos observen las injusticias y traten de revertirlas, así como también crear condiciones para generar prácticas sociales, educativas y culturales alternativas a las dominantes, que posibiliten la construcción de un modelo igualitario.

Sin embargo, las condiciones de la práctica educativa que se producen en contextos de encierro, a menudo entorpecen estos objetivos. Es recurrente que al docente se lo controle en su tarea diaria y se lo coloque en un lugar de asalariado que ejecuta algo que proviene de arriba a cambio de un sueldo mensual. Esto sería contradictorio si queremos educadores transformadores ya que estos requieren de autonomía y no precisamente de control y meros ejecutores de algo que ellos no planificaron ni desearon. 
Otro factor que no puede faltar al momento de presentar posibles respuestas al problema en cuestión es la interpretación de las representaciones sociales presentes tanto en el sistema penitenciario, como en la sociedad en su conjunto.Uno de los grandes obstáculos que se presentan para ejecutar prácticas educativas inclusivas son las políticas dominantes que atribuyen que las causas de la pobreza y de la opresión se deben buscar y encontrar en los mismos pobres, como si ellos eligieran esa situación de vida "son pobres porque quieren". La situación de nuestros estudiantes de contextos de encierro y las representaciones que se construyen desde el discurso con respecto a ellos, pareciera que también los limita al acceso de otras oportunidades como si la condición de encierro determinara todas las demás.

Son muchas las estrategias de enseñanza en las que podemos apoyarnos para lograr un conocimiento crítico, que van desde las preguntas, la narrativa, los estudios de casos hasta la simulación y la enseñanza basada en problemas. Estrategias que pueden promover un aprendizaje crítico relacionado no solo con cuestiones de la vida diaria de nuestros estudiantes sino también con el conocimiento científico. El debate no debe estar ausente en todo esto, el espacio se debe gestar, construir y recobrar aún más valor cuando la propuesta es articular con otras instituciones además de la cárcel.

Por último, consideramos pertinente la creación de ámbitos y espacios reales y concretos para los docentes en los que podamos tomar decisiones y estas puedan ser ejecutadas. Es fundamental establecer la conexión de la sociedad y la educación pública con el sistema penitenciario. Asimismo, si a participación se refiere, la voz de los estudiantes es otro aspecto que no debe faltar. De este modo es necesario encontrar y crear espacios de encuentro entre el sistema penitenciario, los educadores, equipos técnicos, ONG y representantes estudiantiles. El rol de los y las docentes es fundamental e indispensable como articuladores. Solo así podrá avanzarse en el camino hacia una educación inclusiva basada en los derechos humanos.

\section{Referencias bibliográficas}

MINISTERIO DE EDUCACION (2011). El trabajo del educador. Desafios desde una práctica crítica. Buenos Aires, CABA.

GIROUX, H. y ARONOWITZ, A. (1998). La enseñanza y el rol del intelectual transformador en A. Alliaud y L. Duschatzky, Maestros. Formación, práctica y transformación escolar, Buenos Aires: Miño y Dávila.
FREIRE, P. (1999). Política y educación, México: Siglo XXI. 